\title{
La protección de los derechos humanos de personas extranjeras en el juicio contencioso administrativo*
}

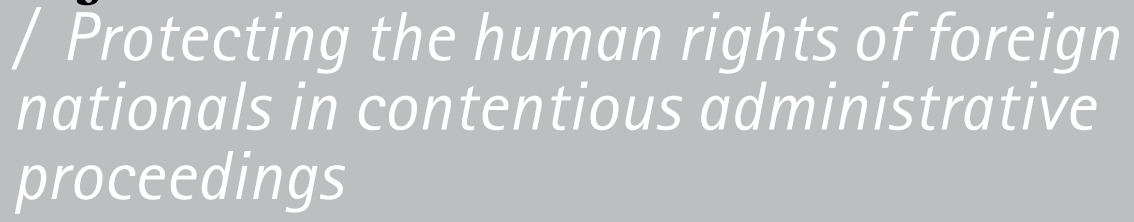

Mauro Pérez Bravo**

\begin{abstract}
RESUMEN
Este artículo pretende destacar los criterios juridicos de las sentencias emitidas por el Tribunal Federal de Justicia Administrativa, como producto de los juicios contenciosos administrativos que se hayan emitido en materia de migración y refugio, en el periodo 2014-2019. Se profundizará en las principales aportaciones de las sentencias emitidas a la luz de la reforma constitucional de 2011 y en los criterios sustentados por el Tribunal Federal de Justicia Administrativa, en los casos resueltos en materia migratoria en donde la autoridad responsable haya sido el Instituto Nacional de Migración. Finalmente, se destacarán los alcances y límites que ha realizado el Tribunal Federal de Justicia Administrativa en la protección de los derechos fundamentales de las personas migrantes.
\end{abstract}

PALABRAS CLAVE: Migración, protección jurisdiccional, juicio de nulidad, reparación del daño, derechos humanos.

\section{ABSTRACT}

The present article aims to highlight the legal criteria for the sentences handed down by the Federal Court of Administrative Justice, from 2014-19, in contentious administrative proceedings relating to migration and refugees. It will present an in-depth examination of the main contributions/repercussions of the sentences handed down, in light of the 2011 constitutional reform and the criteria upheld by the Federal Court of Administrative Justice, in resolved migration cases where the responsible authority was the National Institute of Migration. Finally, the present paper highlights the extent and limits of the Federal Court of Administrative Justice in protecting the fundamental rights of migrants.

KEY WORDS: Migration, jurisdictional protection, nullity trial/nullity suit/annulment proceedings, damages, human rights.

\footnotetext{
* Artículo de investigación. Recibido el 23 de enero de 2020 y aceptado para su publicación el 8 de julio de 2020.

** Abogado de Protección para Migrantes y Refugiados en el Servicio Jesuita a Refugiados, México. / mauro050@ yahoo.com.mx / orcid.org/0000-0002-9303-4730
} 


\section{SUMARIO}

1. Introducción

2. Los tribunales administrativos: juicio de legalidad

3. Juicio contencioso administrativo en materia de migración

4. Conclusiones

\section{Introducción}

En México, la protección de los derechos humanos de las personas extranjeras en situación migratoria, regular o irregular, implica un esfuerzo institucional. Esto requiere de voluntad política, instituciones gubernamentales sólidas, y un marco legal vigente, acorde con una visión que tenga como eje la dignidad de las personas. Todo ello, en función de los parámetros establecidos en la Constitución Política de los Estados Unidos Mexicanos (CPEUM), así como los lineamientos de derecho internacional en materia de derechos humanos.

En el presente trabajo se desarrolla un estudio, en lo particular, de una de estas instituciones del Estado mexicano: el Tribunal Federal de Justicia Administrativa (TFJA). En concreto, nos enfocaremos en la figura jurídica del juicio de nulidad o juicio contencioso administrativo, el cual se substancia precisamente ante el TFJA. El análisis tiene por objetivo ahondar en los alcances y límites de este juicio contencioso administrativo, en una rama del derecho administrativo: el derecho migratorio.

Es decir, se analizan los alcances y límites que tiene el juicio de nulidad seguido ante el TFJA en materia de migración, así como las implicaciones y aportaciones que se pueden obtener a nivel legal, constitucional y convencional. Para ello, metodológicamente, tomamos como objeto de estudio las sentencias emitidas por las diversas salas del TFJA, desde el año 2014 hasta el 21 de junio de 2019.

Decidimos tomar el periodo comprendido entre el 2014 y el 2019 en virtud de que, en México, nos encontramos con varios e importantes acontecimientos en materia de migración, que impactaron en la vida social, política, y jurídica del país entre esos años. Además, tales acontecimientos le dieron nuevos rostros a la migración, la cual dejó de ser exclusiva de hombres que migraban para buscar trabajo en Estados Unidos de América con el fin de mejorar la vida de sus familias, mientras estas se quedaban en sus países de origen.

La migración se diversificó: ahora también hay niñas, niños y adolescentes, personas adultas mayores, personas con discapacidad, personas de la comunidad 
LGBTTTI, mujeres, personas indígenas, etcétera. Nos encontramos entonces ante movimientos humanos que requieren toda una serie de políticas públicas de atención, asistencia social y protección, en el ejercicio de sus derechos fundamentales.

Por lo anterior, consideramos que el último lustro en México ha implicado enormes retos en el campo de la protección de los derechos humanos de todas las personas, en especial, de aquellas que se encuentran en situación de vulnerabilidad, como es el caso de las personas migrantes.

A fin de contar con un número oficial de sentencias emitidas en materia de migración por parte del TFJA, realizamos una solicitud de transparencia a dicho órgano jurisdiccional, el cual, a través del oficio UE-SI-0853/2018 suscrito por el titular de la Unidad de Transparencia del referido Tribunal, proporcionó una lista de 560 expedientes. Estos abarcan el periodo comprendido entre enero de 2014 hasta junio de 2019.

Del total de las sentencias señaladas en el oficio UE-SI-0853/2018, únicamente se pudo tener acceso a 358, pues en el momento de querer acceder a la versión pública de las sentencias en el buscador de la página oficial del TFJA, nos encontramos expedientes repetidos, o que no existía la versión pública de otros tantos. Igualmente, de las 358 sentencias, 33 corresponden a actos emitidos por el Órgano Interno de Control del Instituto Nacional de Migración, y por la Comisión Mexicana de Ayuda a Refugiados.

Las sentencias relativas a estas autoridades no serán objeto de estudio en el presente trabajo, dado que sus actos administrativos versan sobre responsabilidades administrativas de servidores públicos y juicios relativos al reconocimiento de la condición de refugiado. Estos deberían implicar un estudio sistemático y más profundo que, por cuestiones de temporalidad y espacio, no es posible realizar en este momento.

En consecuencia, el grueso de las sentencias que serán analizadas corresponde a 325 sentencias en donde se recurre a actos administrativos emitidos por el Instituto Nacional de Migración. Consideramos que la muestra proporcionada y a la que tuvimos acceso es suficientemente representativa para los fines que buscamos. Como lo veremos en el estudio respectivo, hay criterios jurisdiccionales bien definidos que utilizan las diversas salas del TFJA, encaminados a estudiar la legalidad de los actos administrativos emitidos por la autoridad migratoria mexicana.

Los primeros apartados de este trabajo esbozarán brevemente el origen histórico de los tribunales administrativos, así como su lugar en el marco jurídico mexicano. De esta manera, podremos contar con un panorama más completo sobre la importancia de los tribunales en materia administrativa, en el sistema jurisdiccional mexicano. 
En segundo lugar, estudiaremos brevemente la figura jurídica del juicio de nulidad o juicio contencioso administrativo y cuáles son sus alcances en cuanto al estudio de los actos administrativos, a la luz de los principios de legalidad y buena fe que deben regir el actuar de la administración pública.

Finalmente, en la última parte del presente trabajo, retomaremos los principales criterios que se desprenden de las sentencias emitidas por las salas del TFJA. Asimismo, veremos cuáles han sido los principales actos administrativos que dicho órgano jurisdiccional ha sometido a revisión.

Con lo anterior, buscamos resaltar la importancia del actuar de los tribunales administrativos en la protección de los derechos humanos de las personas migrantes. Ya sea que estos se encuentren en situación migratoria regular o irregular, el acceso a un juicio, a pruebas, y a ser oídos en audiencia son referentes de un Estado constitucional de derecho.

\section{Los tribunales administrativos: juicio de legalidad}

El Estado mexicano, para su funcionamiento y organización, se encuentra dividido en lo que comúnmente denominamos Poder Ejecutivo, Legislativo y Judicial, esto de acuerdo con lo señalado en el artículo 49 de la Constitución Política de los Estados Unidos Mexicanos (сPEum). Este artículo de nuestra Carta Magna es preciso, al señalar que no podrán reunirse dos o más poderes en una sola persona, esto a fin de mantener el equilibrio y la autonomía entre los mismos.

Cada uno de estos poderes tiene una función en particular. En la parte medular que a nosotros nos interesa, el Poder Judicial tiene la función de dirimir controversias entre particulares mediante procesos que denominamos juicios. El Poder Judicial tiene competencia para realizar la revisión constitucional de la normatividad o de los actos de la administración, es lo que denominamos “medios de control constitucional”. De acuerdo con Soto Flores ${ }^{1}$, algunos de los medios de control constitucional que se encuentran establecidos en la normatividad mexicana son:

- El juicio de amparo (artículos 103 y 107 constitucionales)

- Las controversias constitucionales (artículo 105, fracción I)

- Las acciones de inconstitucionalidad (artículo 105, fracción II)

- $\quad$ El juicio político (artículo 110)

Soto Flores, Armando Guadalupe, "La controversia constitucional y la acción de constitucionalidad como medios de control constitucional", en Derecho procesal constitucional, México, Instituto Nacional de Estudios, 2016. 
- El procedimiento seguido ante los organismos públicos autónomos protectores de derechos humanos (artículo 102-B)

Los citados medios de control constitucional tienen precisamente la consigna de limitar el poder público dentro del mismo Estado. Es el Poder Judicial el encargado de velar por que la normatividad que rija al Estado democrático mexicano se encuentre adecuada a la cPEUM, así como a los tratados internacionales en los que México sea parte.

Ahora bien, al Poder Judicial de la Federación, por medio de la Suprema Corte de Justicia de la Nación, tribunales colegiados, unitarios y juzgados de distrito, le corresponde salvaguardar la protección constitucional de los actos de autoridad que afecten la esfera jurídica del gobernado. Ello, a través de un medio de control constitucional en concreto, que conocemos como un juicio constitucional de garantías o juico de amparo:

Se considera indispensable puntualizar que la figura del amparo considerado como un medio de control constitucional que opera contra actos, omisiones o normas generales emitidos por una autoridad que trastoca los derechos humanos de las personas, es un juicio cuyo fundamento lo encontramos en los artículos 103 y 107 de la Constitución Política de los Estados Unidos Mexicanos, es decir, es juicio diseñado exclusivamente para tutelar los derechos humanos del gobernado. ${ }^{2}$

Tenemos entonces un medio de control constitucional que permite a los gobernados hacer frente a los actos de autoridad que, directa o indirectamente, lesionen o afecten los derechos humanos de las personas. Sin embargo, el juicio de amparo -así como el resto de los medios de control constitucional- no es el único medio que tienen las personas para defenderse de los actos de autoridad. Otro medio de defensa es el juicio de nulidad.

¿Cómo y ante quién se tramita el juicio de nulidad? Hemos referido que es el Poder Judicial quien se encarga de dirimir las controversias que surjan entre particulares, mediante juicios a nivel local. Asimismo, que, a través del juicio de amparo, este poder permite la protección constitucional para los gobernados contra los actos de autoridad. No obstante, existe la alternativa de acudir a la vía jurisdiccional, no por violaciones constitucionales, sino por violaciones de orden legal, esto es, acudir a los juicios de nulidad en materia administrativa y fiscal.

\footnotetext{
${ }^{2}$ Hernández Segovia, Arturo, "El Juicio de amparo como garante del derecho en México", Revista lustitia, 2013, p. 275.
} 
Los poderes judiciales locales y el Poder Judicial de la Federación no analizan la legalidad de los actos de la administración pública; para tal efecto existen tribunales especializados: los tribunales administrativos. ¿Cuáles son las características de un tribunal administrativo? Sánchez Pichardo ${ }^{3}$ las enumera de la siguiente manera: a) la creación del tribunal debe tener su fundamento en ley; $b$ ) que dicha ley le otorgue facultades para dirimir conflictos entre los ciudadanos y la autoridad; c) completa autonomía para la determinación de sus resoluciones.

La creación de tribunales especializados para juzgar a la administración pública tiene su origen poco después de la Revolución francesa. Posterior a dicho evento, "los hombres de la revolución tuvieron un especial temor frente a los jueces por cuanto en la etapa previa a la revolución los administradores de justicia de la época se habían convertido en un obstáculo para la aplicación de las políticas del rey". ${ }^{4}$ Es decir, el Poder Judicial, al ser contrapeso de la administración pública, podía detener o suspender los actos emanados por esta, entorpeciendo su funcionamiento y la ejecución de los actos administrativo.

No obstante, los ideales de la Revolución francesa se basaban principalmente en la justicia y en la concepción de un derecho más progresista, que controlara, precisamente, el poder de los gobernantes. De acuerdo con Libardo Rodríguez, así fue como el nuevo Estado francés creó el mecanismo de reclamación "administración-juez", el cual consistía en "que las eventuales reclamaciones contra la administración debían ser presentadas ante ella misma y resueltas por el jefe del ejecutivo". ${ }^{5}$

Para fortalecer este mecanismo de administración-juez, se creó el Consejo de Estado Francés, el cual, con el paso del tiempo, fue tomando importancia e independencia del poder central, contenido en el Ejecutivo. De esta manera, se contaría posteriormente con un órgano, formalmente, dependiente del Poder Ejecutivo, pero, materialmente, tendría un carácter jurisdiccional cuyo principal objetivo sería juzgar a la administración pública. Tenemos entonces en el Consejo de Estado Francés el principal antecedente de lo que en el Estado mexicano conoceremos como tribunales administrativos o de legalidad.

\footnotetext{
${ }^{3}$ Sánchez Pichardo, Alberto C., Los medios de impugnación en materia administrativa. Recursos administrativos, juicio de nulidad, y amparo en materia fiscal y administrativa, México, unAM, 2004, p. 281.

${ }^{4}$ Rodriguez Rodriguez, Libardo, "La explicación histórica del derecho administrativo", en Estudios en homenaje a don Jorge Fernández Ruiz. Derecho Administrativo, México, unam, 2005, p. 297.

${ }^{5}$ Rodriguez Rodriguez, Libardo, "La explicación histórica del derecho administrativo", en Estudios en homenaje a don Jorge Fernández Ruiz. Derecho Administrativo, México, unam, 2005, p. 297.
} 
Estos tribunales son de carácter administrativo precisamente porque su función es juzgar a la administración pública, y son de legalidad porque el análisis de los asuntos que se sometían a su competencia versaban sobre la legalidad o ilegalidad de los actos de la administración pública. Es decir, si un acto administrativo se encontraba ajustado al marco legal correspondiente o si la norma había sido aplicada correctamente. Así, los tribunales administrativos velan porque el principio de legalidad sea aplicado en los actos de la administración pública, con total libertad y autonomía. ${ }^{6}$

En el marco jurídico mexicano actual, el principio de legalidad está contenido en el artículo 14 de la cPEum, de donde podemos desprender los siguientes: ${ }^{7}$

- Su emisión debe ajustarse al procedimiento previsto para tal fin.

- Debe ser conforme a las leyes expedidas con anterioridad al hecho.

- Debe constar por escrito.

- Debe ser emitido por autoridad competente.

- Debe encontrarse debidamente fundado y motivado.

En este punto, los tribunales de legalidad se diferencian de los tribunales constitucionales (scJn, tribunales colegiados, de circuito, jueces de distrito), en virtud de que estos últimos son los que tienen competencia para analizar y juzgar actos del poder público, a la luz de la cPeum. Asimismo, vigilan que el principio constitucional rija el actuar de la autoridad.

La diferencia entre el control de legalidad y el control constitucional de los actos de la administración pública ya no es tan determinante, después de la reforma constitucional de 2011. Gracias a esta reforma, el control de legalidad y el control constitucional de los actos del poder público quedaron bastante integrados por lo que conocemos como el control difuso de la constitución. “Con la expresión 'control difuso' nos referimos a la facultad que tienen todos los órganos jurisdiccionales, en vía de excepción, de estudiar la constitucionalidad de normas generales, especialmente, y omitir su aplicación en un caso concreto o, si se tratare de actos stricto sensu, declarar su nulidad."

Los juicios contenciosos administrativos o juicios de nulidad se substancian ante los tribunales administrativos. A través de la historia jurídica de México, a

\footnotetext{
${ }^{6}$ Cfr. Sánchez Pichardo, Alberto C., Los medios de impugnación en materia administrativa. Recursos administrativos, juicio de nulidad, y amparo en materia fiscal y administrativa, México, unAm, 2004, p. 269.

7 Cfr. Figueroa Ávila, Enrioue, "Controles de convencionalidad y de legalidad. Hacia un nuevo modelo de la justicia electoral", Revista Justicia Electoral, 2011, 128-129.

${ }^{8}$ Sánchez GIL, Rubén A., "El control difuso de la constitucionalidad en México. Reflexiones en torno a la tesis P./J. 38/2002", Revista Cuestiones Constitucionales, 2004, p. 206.
} 
nivel federal, dichos tribunales administrativos han ido cambiando su nombre y adecuando y ampliando sus facultades, de acuerdo con los retos contemporáneos que implica el derecho administrativo y fiscal. Entre las principales evoluciones que ha tenido el ahora Tribunal Federal de Justicia Administrativa, encontramos las siguientes:

- $\quad$ 1937, Ley de Justicia Fiscal, Tribunal Fiscal de la Federación

- 2000, Ley Orgánica del Tribunal, Tribunal Federal de Justicia Fiscal y Administrativa

- 2016, Nueva Ley Orgánica del Tribunal, Tribunal Federal de Justicia Administrativa

Así, el Tribunal Federal de Justicia Administrativa, es decir, "la justicia administrativa federal o todo lo contencioso administrativo federal [...], procede contra todas las resoluciones administrativas de la Administración Pública Federal centralizada o paraestatal". ${ }^{9}$

Hasta el momento, hemos resaltado la importancia que tienen los tribunales administrativos como controles del poder público, en donde los gobernados pueden someter, ante una autoridad jurisdiccional, la revisión de la legalidad de un acto de autoridad.

Ahora bien, nuestro objetivo principal es destacar esta revisión del poder público para la protección de personas en situación de vulnerabilidad, en particular, de las personas migrantes. Por ello, centraremos ahora nuestra atención en la protección jurídica que han realizado los tribunales administrativos, en este caso, el Tribunal Federal de Justicia Administrativa, respecto a las personas migrantes en situación irregular en México.

\section{Juicio contencioso administrativo en materia de migración}

Como lo señalamos en la parte introductoria del presente trabajo, la metodo140 logía que seguimos para el análisis de las sentencias, y los criterios emitidos por el Tribunal Federal de Justicia Administrativa, es mixta. Se compone por el análisis descriptivo y cualitativo de la versión pública de las sentencias emitidas en una temporalidad concreta, 2015 hasta junio de 2019, en donde la autoridad demandada es el Instituto Nacional de Migración.

\footnotetext{
${ }_{9}^{9}$ Nava Negrete, Alfonso, "70 años del Tribunal Administrativo Federal de México", Revista de la Facultad de Derecho UNAM, p. 255.
} 
A fin de que los actos del Instituto Nacional de Migración puedan ser revisados por una autoridad jurisdiccional, en primer lugar, habrá que diferenciar entre un acto administrativo y un acto de la administración pública.

Todo acto administrativo es un acto de la administración pública, pero no todo acto de la administración pública es un acto administrativo. Para mayor claridad, acudamos a la definición por antonomasia que tenemos sobre acto administrativo, propiamente dicho, que nos aporta Miguel Acosta Romero:

El acto administrativo es una manifestación unilateral y externa de la voluntad, que expresa una decisión de una autoridad administrativa competente, en ejercicio de la potestad pública. Esta decisión crea, reconoce, modifica, transmite, declara o extingue derechos u obligaciones, es generalmente ejecutivo y se propone satisfacer el interés general. ${ }^{10}$

Derivado de lo anterior, un acto administrativo, para ser tal, tiene que crear, modificar, transmitir o extinguir obligaciones o derechos. Un acto de la administración pública que no reúne tales características es simplemente eso, un acto de la administración pública. Así, el acto de recolectar la basura es una actividad de la administración pública, pero dicho acto no crea o extingue derecho $\mathrm{u}$ obligaciones, por ello, no podría considerarse un acto administrativo propiamente dicho.

En cambio, el requerimiento fiscal de algún impuesto, que conlleva aparejada una ejecución, sí es un acto administrativo, toda vez que implica que el contribuyente realice forzosamente el pago de un impuesto al que se encuentra obligado, y en el caso de ser omiso, existe una penalización, una multa, por ejemplo. En general, las características del acto administrativo son las siguientes: ${ }^{11}$

- Presunción de legitimidad o legalidad

- Ejecutoriedad, exigibilidad y fuerza intrínseca del acto

- Firmeza administrativa

- Ejecutividad

- Publicidad

- Derogación, sujeta a reglas especiales

- Tipicidad

- Nominatividad

\footnotetext{
${ }^{10}$ Acosta Romero, Miguel, "Teoria general del derechos administrativo", México, Porrúa, 1995, p. 749.

${ }^{11}$ Tron Petit, Jean Claude y Ortiz Reyes, Gabriel, La nulidad de los actos administrativos, México, Porrúa, 2015, p. 79.
} 
Todo acto administrativo, además, deberá cumplir con los requisitos legales establecidos en el artículo 3 de la Ley Federal de Procedimiento Administrativo. Sobre este punto es preciso ahondar, pues, en caso de que falte alguno de estos requisitos establecidos en la normatividad, el acto administrativo podría ser declarado nulo por autoridad competente. También a través de los procesos jurídicos correspondientes, un acto administrativo podría ser declaro nulo y sin efecto, mediante el juicio de nulidad substanciado ante los tribunales administrativos, tal y como lo hemos referido en líneas anteriores.

Ahora bien, señalemos qué es el juico contencioso administrativo:

El enjuiciamiento de la administración pública por parte, obviamente, de un órgano jurisdiccional; es decir, constituye la serie de actos que tienden a resolver mediante el dictado de una sentencia, una controversia suscitada con motivo de un acto administrativo que es tachado de ilegal, cuya finalidad es, como dice Andreozzi, la obtención de una resolución judicial de índole definitivo que reconozca el derecho subjetivo conculcado. ${ }^{12}$

Como ya lo advertimos en líneas anteriores, es facultad de los tribunales administrativos juzgar los actos de la administración pública que así sean sometidos a su escrutinio. En el caso particular que nos ocupa, la autoridad administrativa migratoria (Instituto Nacional de Migración) forma parte de la Administración Pública Federal, esto de acuerdo con lo señalado en los artículos 18 y 19 de la Ley de Migración. En consecuencia, los actos emanados del Instituto Nacional de Migración son susceptibles de ser impugnados a través del juicio de nulidad o juicio contencioso administrativo. Como se señaló en líneas anteriores, en virtud de que es un acto administrativo que crea, modifica o extingue obligaciones.

En este tenor, los actos administrativos emitidos por el Instituto Nacional de Migración deben cumplir necesariamente con los requisitos normativos que señalamos en líneas anteriores, a fin de que dichos actos sean legales y válidos. El artículo 20 de la Ley de Migración contiene las facultades que el Instituto Nacional de Migración tiene en relación con su actividad administrativa. Entre estas facultades, destacamos las siguientes:

${ }^{12}$ Iturbe Rivas, Arturo, Elementos de derecho procesal administrativo, México, Porrúa, 2004, p. 120. 
- Vigilar la entrada y salida de personas al territorio de los Estados Unidos Mexicanos, y revisar su documentación

- Resolver sobre la internación, estancia, y salida del país de los extranjeros

- Conocer, resolver y ejecutar la deportación o retorno asistido de extranjeros

- Imponer las sanciones prevista en su ley

Estas facultades que se encuentran establecidas en la Ley de Migración se materializan mediante el procedimiento administrativo correspondiente. Esto da origen al acto administrativo propiamente, en este caso, del Instituto Nacional de Migración.

El Instituto Nacional de Migración emite diversos actos administrativos, de acuerdo con sus facultades, principalmente las señaladas en líneas anteriores. Como lo advertimos, una de las características de los actos administrativos es que son recurribles, es decir, contamos con medios de defensa legales debidamente establecidos y regulados en la ley. Luego entonces, las personas afectadas por los actos administrativos emitidos por el Instituto Nacional de Migración tienen derecho a impugnarlos, y que dichos actos administrativos sean sometidos a la revisión de su legalidad.

De acuerdo con el estudio que realizamos de las sentencias emitidas por el Tribunal Federal de Justicia Administrativa y la información proporcionada por él, los actos administrativos emitidos por el Instituto Nacional de Migración, entre 2014 y junio de 2019, se agruparon en diferentes rubros (véase la tabla 1 en el apéndice).

De acuerdo con lo que observamos en la lectura de las sentencias emitidas por el TFJA, la tendencia de los actos administrativos emitidos por el Instituto Nacional de Migración es de carácter negativo. Es decir, la mayoría de los actos administrativos enunciados van encaminados al no reconocimiento de un derecho para las personas migrantes, por parte de las autoridades administrativas. En consecuencia, dichos actos son susceptibles de impugnarse en la vía contenciosa administrativa. No obstante, estos actos administrativos que niegan derechos no son los más recurridos. La gráfica 1 (véase el apéndice) permite dimensionar los tres principales actos administrativos más impugnados en las 325 sentencias.

Como podemos apreciar, el mayor número de actos administrativos impugnados mediante el juicio de nulidad corresponde a multas que el Instituto Nacional de Migración impuso a personas morales. En segundo y tercer lugar, los actos impugnados versaron sobre negativas para cambiar la condición a 
residente temporal por unidad familiar y para regularizar la situación migratoria por unidad familiar. Esta estadística nos permite dimensionar el poco o escaso acercamiento al juicio de nulidad como mecanismo para la protección de los derechos humanos de las personas migrantes.

En la introducción del presente trabajo, dimos cuenta de cómo México es un país de tránsito de personas migrantes, principalmente provenientes del denominado Triángulo Norte de Centroamérica (Guatemala, El Salvador, Honduras). El flujo migratorio no es menor, tal y como se refleja en las detenciones que realiza el Instituto Nacional de Migración de personas extranjeras en situación irregular (véase la tabla 2 en el apéndice).

Podemos observar que es sumamente importante el flujo migratorio proveniente de Centroamérica, que atraviesa México en su camino hacia Estados Unidos de América. Ello contrasta enormemente con el reducido número de casos sometidos a la competencia del Tribunal Federal de Justicia Administrativa en la misma temporalidad. En cambio, como organismo público no jurisdiccional de protección de derechos humanos, la Comisión Nacional de los Derechos Humanos tuvo los siguientes registros en cuanto a número de quejas presentadas en el programa de atención a migrantes de la quinta visitaduría (véase la tabla 3 en el apéndice). ${ }^{13}$

No es objeto de este trabajo realizar un comparativo entre diversos organismos constitucionales como lo son la cNDH y el Tribunal Federal de Justicia Administrativa, pues sus procedimientos guardan naturalezas jurídicas diversas, máxime que el primero reviste el carácter de no jurisdiccional y el segundo sí. Empero, señalamos las estadísticas anteriores para enfatizar el número tan alto de quejas y problemáticas jurídicas en donde se ven involucradas personas migrantes, y su mínimo acercamiento al juicio de nulidad como medio de defensa.

En efecto, el juicio de nulidad requiere de consideraciones técnicas y muy específicas por las cuales es necesaria la asistencia de profesionales del derecho,

\footnotetext{
${ }^{13}$ La Comisión Nacional de los Derechos Humanos está estructurada de manera que, además de otras oficinas, cuenta con seis visitadurias generales. Cada visitaduría general tiene asignados determinados programas de atención para personas con discapacidad, personas indígenas, personas LGBTTI, por mencionar algunas. En el caso de las personas migrantes, este programa especial se encuentra asignado a la quinta visitaduria. Esta fue creada el 1 de enero de 2005, mediante acuerdo publicado en el Diario Oficial de la Federación. De esta quinta visitaduría dependen tres programas: a) programa de atención a migrantes; b) programa de agravio a periodistas y defensores civiles; y c) programa contra la trata de personas. Ahora bien, el informe anual de la CNDH señala los números de expedientes radicados dentro del Programa de Atención a Migrantes de la quinta visitaduría de la Comisión Nacional de los Derechos Humanos, sin embargo, se debe precisar que algunos son expedientes de queja, otras son remisiones y otras más orientaciones. Además, no solamente son expedientes en donde se ven involucradas personas extranjeras; aunque en menor medida, también se atiende a población nacional que ha tenido quejas de autoridades como el Instituto Nacional de Migración.
} 
a fin de que las personas migrantes puedan tener acceso a este recurso jurídico. Por ello, es concluyente que el mayor número de asuntos migratorios sometidos ante la competencia del Tribunal Federal de Justicia Administrativa sean aquellos en donde se ven involucradas personas morales con la solvencia suficiente para impugnar actos administrativos que les imponen multas.

$\mathrm{Al}$ analizar las sentencias en donde se impugnaron multas realizadas a las personas morales, podemos advertir que se originaron, principalmente, por irregularidades en los procedimientos para la internación, o por rechazo a personas extranjeras para ingresar a territorio mexicano. Ello nos hace concluir que las multas impuestas por parte del Instituto Nacional de Migración son realizadas principalmente a las aerolíneas comerciales.

Como ejemplo de lo anterior, tomemos las siguientes sentencias de tres expedientes dictadas por diversas salas del Tribunal Federal de Justicia Administrativa: a) 24268/16-17-12-3 emitida por la Décima Segunda Sala Regional Metropolitana; b) 20859/16-17-06-1 emitida por la Sexta Sala Regional Metropolitana; y c) 6206/17-17-09-3, emitida por la Novena Sala Regional Metropolitana.

En la primera sentencia, el motivo de la multa a la persona moral fue que, en las actas de rechazo aéreo, la autoridad administrativa migratoria se percató de que una persona extranjera carecía de la documentación idónea para su ingreso al país. Esto contravendría el artículo 248 del Reglamento de la Ley de Migración, según el cual las empresas que trasladen a territorio mexicano, a personas que carezcan de documentación válida para su respectivo ingreso, serán sancionadas con una multa que puede ir desde los mil a los diez mil días de salario mínimo vigente en la Ciudad de México.

En la segunda sentencia, la multa por la cual se sancionó a la persona moral se debió a que: "la aerolínea en mención no verificó que la persona extranjera rechazada contara con la documentación válida al momento de transportarla", tal y como lo determina el Instituto Nacional de Migración en el oficio 376/016 que se encuentra integrado en la sentencia de mérito.

En la tercera sentencia, el sentido de la multa es el mismo: se multó a una aerolínea. De acuerdo con el acto impugnado, la persona moral incumplió con el artículo 44 de la Ley de Migración, el cual obliga a las empresas de transporte aéreo a verificar que los extranjeros que transporten cuenten con la documentación válida y vigente para ingresar al país.

El artículo 52 de la Ley Federal de Procedimiento Contencioso Administrativo, de manera muy general, señala que los sentidos en los cuales puede dictarse una sentencia del Tribunal Federal de Justicia Administrativa son: a) reconocer validez del acto; $b$ ) declarar la nulidad de la resolución para efectos; c) declarar 
la nulidad lisa y llana del acto; d) modificar la cuantía o reducir la sanción; e) condenar al pago de una indemnización (responsabilidad patrimonial del Estado).

En las tres sentencias en comento, se declaró la nulidad lisa y llana de los actos impugnados. Esto significa que el acto reclamado dejó de surtir efectos y dejó de existir en la vida jurídica. De tal modo, la autoridad emisora tiene la obligación de abstenerse de aplicar o ejecutar dicho acto. ${ }^{14}$

En el caso de las tres sentencias que fueron anuladas por el Tribunal Federal de Justicia Administrativa, detectamos que las resoluciones se dictaminaron en ese sentido por falta de fundamentación o inadecuada motivación. De acuerdo con un criterio ya bien establecido por la Suprema Corte de Justicia de la Nación en la jurisprudencia 394216, de la Séptima Época, emitida por la Segunda Sala, debemos entender por fundamentación que en el acto de autoridad -en este caso, en el acto administrativo-, debe expresarse con claridad e indubitablemente el precepto legal aplicable al caso.

De acuerdo con el mismo criterio, debemos entender por motivación que deben señalarse con precisión las circunstancias particulares al caso, es decir, las circunstancias de tiempo, lugar y modo que llevaron a la emisión de dicho acto de autoridad. ${ }^{15}$

Del total de multas impuestas por el Instituto Nacional de Migración a personas morales, casi todas fueron anuladas lisa y llanamente. Solo en 5\% se decretó la validez del acto impugnado, tal y como se aprecia en la gráfica 2 (véase el apéndice).

Lo anterior ejemplifica que la autoridad migratoria, en el momento de emitir sus actos administrativos, es deficiente en cuanto a su fundamentación y motivación, lo cual conlleva a que dichos actos puedan ser anulados mediante un juicio de nulidad. En la mayoría de los casos estudiados, se anularon los actos administrativos suscritos por servidores públicos del Instituto Nacional de Migración porque aquellos no contaban con las facultades necesarias para suscribirlos. Por ejemplo, en la sentencia formulada dentro del expediente 24268/16-17-12-3, la parte actora impugnó el acto consistente en:

La resolución de fecha 02 de mayo de 2016, contenida en el oficio número 1147/016, dictada en el expediente administrativo número AR/

\footnotetext{
${ }^{14}$ Criterio adoptado por la Segunda Sala de la Suprema Corte de Justicia de la Nación en los considerandos de la contradicción de tesis 06/98 de la que provino la tesis 2a/J. 88/99. Tron Petit, Jean Claude y Ortiz Reyes, Gabriel, La nulidad de los actos administrativos, México, Porrúa, 2015, p. 406.

${ }^{15}$ Suprema Corte de Justicia de la Nación, Segunda Sala, tesis 260, 1995, Semanario Judicial de la Federación. Disponible en: https://sjf.scjn.gob.mx/sjfsist/paginas/DetalleGeneralV2.aspx?id=394216\&tClase=DetalleTesisBL
} 
SL2301/100000/2016, por el Delegado Local Terminal II Aeropuerto Internacional de Cancún en la Delegación Federal en Quintana Roo, del Instituto Nacional de Migración, a través del cual se le impone una sanción pecuniaria en cantidad de $\$ 74,040.00 .{ }^{16}$

La Décima Segunda Sala Regional del Tribunal Federal de Justicia Administrativa determinó que, si bien la autoridad demandada en el expediente de mérito fundó su determinación en los artículos 14 inciso A, fracción XIII, inciso B, fracción xxv de la Ley de Migración, dichos preceptos normativos únicamente facultaban a la autoridad para el caso de imponer y notificar sentencias. Pero no así para iniciar procedimientos que den origen a la sanción impuesta, es decir, para emitir el acuerdo de inicio correspondiente.

Asimismo, el Tribunal Federal de Justicia Administrativa distingue en el acto administrativo que el procedimiento fue iniciado en contra de la parte actora derivado de que esta no verificó que la persona extranjera que transportaba contara con la documentación adecuada para ingresar a territorio mexicano, de acuerdo con lo asentado en el artículo 15, apartado B, fracción Ix de la Ley de Migración, sin que esta normatividad fuera señalada en el acto administrativo.

En cambio, la autoridad administrativa fundó su actuar en el artículo 99 segundo párrafo de la Ley de Migración, que prevé el alojamiento temporal de un extranjero que no acredita su situación migratoria, para la regularización de su estancia o la asistencia para el retorno. Lo anterior entonces deviene en una incongruencia entre los fundamentos establecidos en el acto administrativo y sus motivos. En general, las multas impuestas por el Instituto Nacional de Migración adolecen en este punto por no fundamentar adecuadamente su competencia y facultades.

Como podemos apreciar en la gráfica 3, la efectividad del juicio de nulidad para revisar la legalidad de los actos del Instituto Nacional de Migración, en general, es bastante alta. En el total de sentencias estudiadas, podemos apreciar que únicamente 13\% de los actos administrativos del Instituto fueron declarados válidos. La gran mayoría fueron declarados nulos, lisa y llanamente, y constituyeron otro porcentaje elevado aquellos que fueron declarados nulos para efectos de que la autoridad corrigiera las deficiencias encontradas (véase la gráfica 3 en el apéndice).

Pese a que la mayoría de los casos sometidos ante el Tribunal Federal de Justicia Administrativa en materia de migración tiene que ver con multas

\footnotetext{
${ }^{16}$ Información proporcionada por el Tribunal Federal de Justicia Administrativa mediante oficio UE-SI-0853/2018.
} 
impuestas a personas morales, encontramos expedientes que consideramos relevantes, en virtud del contenido mismo del acto administrativo, el razonamiento que hizo la sala correspondiente y la resolución de la sentencia.

Tomemos el caso del expediente 229/15-13-01-5 substanciado ante la Sala Regional del Golfo. En este expediente, el acto impugnado fue una resolución dictada dentro de un recurso de revisión. Se resolvió confırmar el oficio 2000679 por medio del cual, se le negó la expedición de visa por oferta de empleo a la persona migrante, al no cumplir los requisitos aplicables a la condición de estancia de residente temporal.

Debemos considerar que, en este juicio, la autoridad demandada (delegado federal del Instituto Nacional de Migración en Veracruz) no contestó la demanda entablada en su contra y no aportó el expediente administrativo. Luego entonces, en términos del artículo 45, párrafo segundo, de la Ley Federal de Procedimiento Contencioso Administrativo, se tuvieron por ciertos los hechos que la parte actora pretendía probar.

Aunque la autoridad omitió contestar la demanda, rescatamos de la sentencia aludida el que la Sala Regional del Golfo determinara que la autoridad demandada había discriminado a la persona extranjera, a quien había negado la visa de trabajo. Es decir, un tribunal de legalidad sentenció y protegió un derecho humano fundamental: derecho a la no discriminación. Aunado a lo anterior, hacemos énfasis en el hecho de que la Sala Regional del Golfo desarrolló sus argumentaciones, basándose no solo en la Ley de Migración, sino en ordenamientos internacionales como lo son el Convenio sobre la Discriminación (ocupación y empleo), y el Protocolo Adicional a la Convención Americana sobre Derechos Humanos en materia de Derechos Económicos Sociales y Culturales "Protocolo de San Salvador".

La Sala Regional del Golfo, después de fundamentar su sentencia en la normatividad señalada, concluyó que "Todos los migrantes tienen derecho a ser tratados sin discriminación alguna, esto es, está prohibida toda práctica discriminatoria que tenga por objeto o efecto impedir o anular el reconocimiento o ejercicio de los derechos y la igualdad real de oportunidades".

Nos encontramos ante un ejercicio real y efectivo de protección a los derechos humanos de personas extranjeras, ya que fue la misma Sala quien afirmó que el Instituto Nacional de Migración discriminó a la persona extranjera por no tener la secundaria terminada y no hablar el español para realizar las actividades del trabajo que le fue ofertado. En efecto, dicha resolución del Instituto Nacional de Migración es discriminatoria, pues condiciona la oferta laboral a un nivel educativo e idioma, cuestiones que no eran determinantes para el trabajo que le ofrecían. 
Además de los ordenamientos señalados, la Sala basó el dictado de su sentencia en los siguientes documentos: "Protocolo iberoamericano de actuación judicial para mejorar el acceso a la justicia de personas con discapacidad, migrantes, niñas, niños, adolescentes, comunidades, y pueblos indígenas", "Protocolo de actuación para quienes imparten justicia en casos que afecten a personas migrantes y sujetas de protección internacional”, y en la "Opinión consultiva OC-18/13 emitida por la Corte Interamericana de Derechos Humanos relativa a la condición jurídica y derechos de los migrantes indocumentados".

Es de suma importancia considerar este antecedente, ya que el mismo Tribunal Federal de Justicia Administrativa, a través de su Sala Regional del Golfo, asumió que "se encuentra obligada a observar en el proceso de justicia en el que están involucrados migrantes, el principio de no discriminación, así como adoptar las medidas positivas para revertir o cambiar situaciones discriminatorias existentes en las personas". ${ }^{17}$ Consecuentemente, la Sala Regional, a fin de subsanar la discriminación cometida por el Instituto Nacional de Migración, procedió a condenarlo para que resolviera en sentido favorable la solicitud de trámite migratorio para la internación de extranjeros número de pieza 27344855 , NUT $^{18} 2095222$.

Vemos, entonces, un vasto campo de acción que se puede explorar en materia de derechos humanos de personas migrantes. Acudir al Tribunal Federal de Justicia Administrativa conlleva especificaciones técnicas y, en muchas ocasiones, erogar gastos que son limitados o casi imposibles de solventar para personas migrantes que vienen huyendo de la pobreza, violencia e inseguridad que impera en sus países. No obstante, consideramos que podemos ir planteando rutas de estudio o de oportunidad para que, poco a poco, el juicio de nulidad sea un mecanismo al que se pueda acceder con mayor facilidad, en especial, para las personas que se encuentran en situación de vulnerabilidad, como es el caso de las personas extranjeras en situación migratoria irregular.

\section{Conclusiones}

Con base en todo lo expuesto, podemos concluir que el juicio contencioso administrativo es un medio jurídico de defensa que no ha sido explorado, utilizado y aprovechado en sus alcances, como mecanismo de protección de derechos humanos de las personas migrantes.

\footnotetext{
${ }^{17}$ Con información proporcionada por el Tribunal Federal de Justicia Administrativa mediante oficio UE-SI-0853/2018.

${ }^{18}$ Número único de trámite.
} 
En efecto, existen retos que se tienen que afrontar y aceptar en cuanto a la accesibilidad del juicio contencioso administrativo, como mecanismo de protección de derechos humanos de las personas migrantes. En primer lugar, detectamos que el reto mayor - del cual probablemente derivan los demás- es que el juicio de nulidad requiere de procedimientos técnicos y precisos.

Esto significa que se requiere un especialista en la materia (un abogado en derecho administrativo), que conozca la ley y las instancias a las que se debe acudir para tramitar el juicio de nulidad. Para una persona migrante que se encuentre detenida en una estación migratoria, será necesaria la contratación de un profesional del derecho, y posiblemente requiera erogar recursos económicos para ello. Sin embargo, la mayoría de las personas migrantes salen de sus países de origen, precisamente, debido a la pobreza que padecen en ellos. Por tanto, acceder a un profesional del derecho administrativo, y pagarlo con recursos propios, prácticamente escaparía de sus posibilidades.

No obstante, gran parte de la ayuda jurídica que se les proporciona a las personas migrantes - en situación irregular principalmente- proviene de organizaciones de la sociedad civil que cuentan con abogados capaces de brindar acompañamiento jurídico, sin costo alguno para estas personas. De este modo, dichas organizaciones de la sociedad civil podrían ser el puente para que los migrantes accedan a un medio de defensa, como lo es el juicio de nulidad.

Como segundo reto, consideramos que se requiere una mayor difusión del juicio contencioso administrativo. Asimismo, pensamos que se debe rescatar todo el aporte jurídico y de protección de garantías y derechos humanos que se pueden albergar en los criterios y razonamientos que encontramos en las sentencias emitidas por las diversas salas del Tribunal Federal de Justicia Fiscal y Administrativa.

Finalmente, el tercer reto que hemos de enfrentar quienes consideramos el juicio de nulidad como un mecanismo protector de derechos, para personas extranjeras en situación migratoria irregular, es que estas tienen una condicionante que determina fuertemente su decisión de acudir a los tribunales: el tiempo de encierro en una estación migratoria.

No es fácil para las personas estar privadas de su libertad, máxime cuando no cometieron delito alguno. En este sentido, están privadas de su libertad por cometer faltas administrativas y, aunado a ello, se encuentran en un país que no es el propio, separados de sus familias y con la incertidumbre sobre su futuro. Promover algún recurso jurídico, en este caso el juicio de nulidad, conllevaría a prolongar su estancia encerrados en la estación migratoria, y no siempre la resolución los favorecería. Es decir, no tendrían la certeza de que mediante el juicio de nulidad se garantice su permanencia en territorio mexicano. 
Como se mencionó en el cuerpo del presente artículo, al menos en las sentencias estudiadas, quienes tienen acceso al juicio de nulidad son personas morales. No se cuenta con el dato de cuántos migrantes de nacionalidad hondureña, guatemalteca o salvadoreña han sido beneficiados con las sentencias dictadas por el Tribunal Federal de Justicia Administrativa. Esto es debido a que se carece de ese registro estadístico y no existe normatividad que obligue al tribunal a llevar un recuento a tal detalle. De ahí que sea un desafío capital el hecho de que personas en situación de vulnerabilidad puedan acceder a este mecanismo de defensa jurídico, y no solamente personas morales con recursos económicos para contratar a especialistas o profesionales del derecho.

En materia de derecho administrativo y migratorio, podremos encontrar una riqueza de criterios jurídicos en relación con la fundamentación y adecuada motivación de actos administrativos que afectan la situación jurídica de las personas migrantes. Estos criterios permiten estudiar los actos administrativos en cuanto a su legalidad, es decir, las autoridades administrativas pueden adecuar correctamente la situación jurídica -en particular de las personas migrantes- al marco legal aplicable. Así, no solo aplica el ejercicio discrecional de dichas autoridades en el momento de emitir un acto administrativo, pues esto conllevaría a ilegalidades y posibles actos de discriminación y violación a derechos humanos.

Consideramos que la labor de los tribunales administrativos abona a una cultura de la legalidad, y no solamente en un nivel nacional sino, incluso, a nivel internacional. Esto debido a que coadyuva a consolidar un auténtico Estado democrático de derecho, en donde las autoridades administrativas son sometidas al riguroso estudio que se realiza en los tribunales administrativos. De este modo, se busca que los derechos humanos de todas las personas, nacionales y extranjeros, sean respetados y puedan ser ejercidos sin discriminación, acorde a los lineamientos establecidos en la Constitución Política de los Estados Unidos Mexicanos.

\section{Bibliografía}

Acosta Romero, Miguel, “Teoría general del derechos administrativo”, México, Porrúa, 1995.

Figueroa Ávila, Enrique, "Controles de convencionalidad y de legalidad. Hacia un nuevo modelo de la justicia electoral”, Revista Justicia Electoral, 2011.

HernÁndez Segovia, Arturo, "El Juicio de amparo como garante del derecho en México", Revista Iustitia, 2013, p. 275. 
Iturbe Rivas, Arturo, Elementos de derecho procesal administrativo, México, Porrúa, 2004.

Jean Claude y Ortiz Reyes, Gabriel, La nulidad de los actos administrativos, México, Porrúa, 2015

Nava Negrete, Alfonso, "70 años del Tribunal Administrativo Federal de México", Revista de la Facultad de Derecho UNAM.

Rodríguez Rodríguez, LIBARDo, "La explicación histórica del derecho administrativo", en Estudios en homenaje a don Jorge Fernández Ruiz. Derecho Administrativo, México, UnAM, 2005.

SÁnchez Gil, RubÉn A., "El control difuso de la constitucionalidad en México. Reflexiones en torno a la tesis P./J. 38/2002”, Revista Cuestiones Constitucionales, 2004.

SÁnchez Pichardo, Alberto C., Los medios de impugnación en materia administrativa. Recursos administrativos, juicio de nulidad, y amparo en materia fiscal y administrativa, México, UNAM, 2004.

Soto Flores, Armando Guadalupe, "La controversia constitucional y la acción de constitucionalidad como medios de control constitucional”, en Derecho procesal constitucional, México, Instituto Nacional de Estudios, 2016.

Suprema Corte de Justicia de la Nación, Segunda Sala, tesis 260, 1995, Semanario

Judicial de la Federación. Disponible en: https://sjf.scjn.gob.mx/sjfsist/paginas/ DetalleGeneralV2.aspx?id=394216ctClase=DetalleTesisBL

Tron Petit, Jean Claude y Ortiz Reyes, Gabriel, La nulidad de los actos administrativos, México, Porrúa, 2015.

\section{Apéndice}

\section{Tabla $1^{19}$}

1. Desechó recurso de revisión.

2. Desechó trámite migratorio y se ordenó la salida del país.

3. Determina deportación.

\footnotetext{
${ }^{19}$ Esta clasificación de los actos administrativos obedece a la lectura que realizamos de las 325 sentencias emitidas por las diversas salas del Tribunal Federal de Justicia Administrativa. El nombre que señalamos en el listado no es exactamente el que se señala en las sentencias; atiende al contenido del acto y cómo es que las salas lo mencionan en cada una de sus sentencias. Es importante señalar esto, puesto que no proponemos una lista dogmática y definitiva; dependiendo de las lecturas que se hagan sobre las sentencias, se irá modificando la clasificación. Quisimos conservar el mayor grado de apego a la lectura de la sentencia, a fin de llevar a cabo nuestro listado. Como podrá observarse, en varios casos, los actos administrativos se repiten o son muy similares, como en el caso de las resoluciones administrativas y los recursos de revisión. No obstante, quisimos señalar así los actos administrativos para resaltarlos y, precisamente, enfatizar cómo ha resuelto el TFA y los criterios jurídicos que podríamos rescatar de las sentencias.
} 
4. Determinó desechar trámite de regulación migratoria.

5. Falta de pago en facturas.

6. Improcedente reclamación por responsabilidad patrimonial del Estado.

7. Impuso multa a persona moral.

8. Negativa ficta regularización migratoria.

9. Negó actualización de la constancia de inscripción del empleador.

10. Negó actualización de la constancia de inscripción del empleador.

11. Negó cambio de condición de residente temporal por unidad familiar.

12. Negó cambio de lugar de trabajo.

13. Negó expedición de documento migratorio extemporáneo.

14. Negó expedición de documento migratorio por oferta de empleo.

15. Negó la expedición de documento migratorio por canje.

16. Negó la expedición de documento migratorio por renovación.

17. Negó regularización migratoria.

18. Negó regularización migratoria por razones humanitarias.

19. Negó regularización migratoria por tener documentos vencidos o por realizar actividades no autorizadas.

20. Negó regularización migratoria por unidad familiar.

21. Niega cambio a residente temporal por programa de regularización migratoria.

22. Niega cambio a residente temporal por unidad familiar.

23. Niega cambio de residente temporal a residente permanente.

24. Niega declaratoria de inmigrado.

25. Niega la devolución de billete de depósito.

26. Niega reposición de documento por robo o extravío.

27. No se reconoce la condición de refugiado y se niega la protección complementaria.

28. Recurso de revisión desecha solicitud de reposición de documento migratorio.

29. Resolución administrativa.

30. Resolución de recurso de revisión. Cambio de condición de estancia.

31. Resolución de responsabilidad administrativa.

32. Resolución de recurso de revisión que confirma la negativa de expedición de condición de residente por renovación.

33. Resolvió recurso de revisión.

34. Resolvió tener por desistido al recurrente.

35. Responsabilidad patrimonial del Estado.

36. Sobreseyó recurso de revisión. 


\section{Gráfica 1}

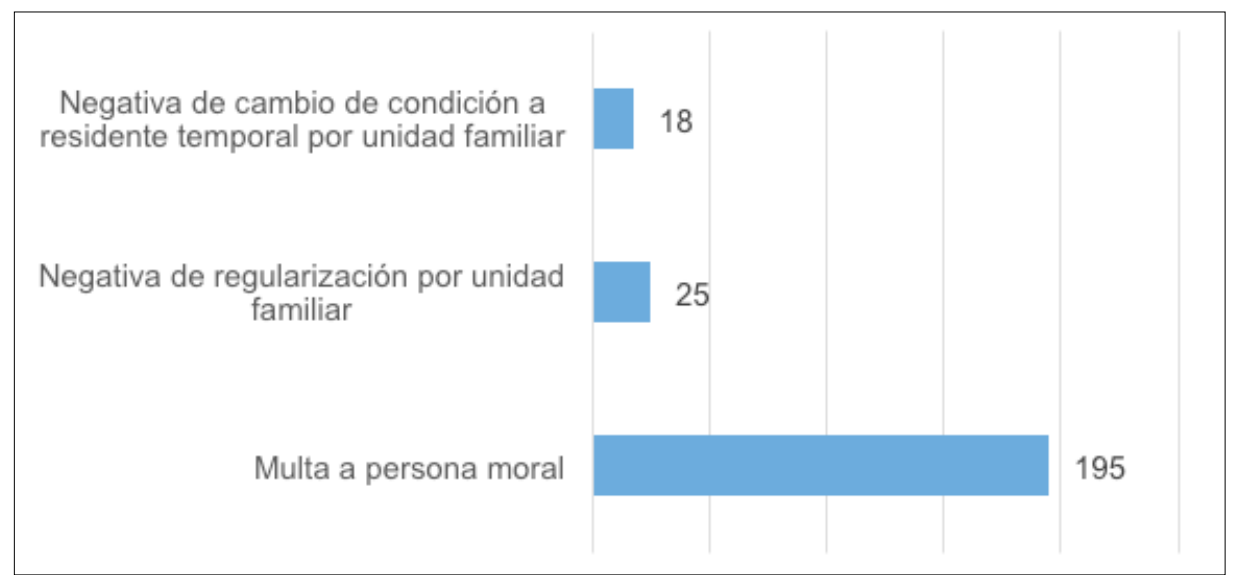

Fuente: Elaboración propia con información proporcionada por el Tribunal Federal de Justicia Administrativa mediante oficio UE-SI-0853/2018.

Tabla 2

\begin{tabular}{|c|c|c|c|c|c|c|}
\hline Concepto & 2014 & 2015 & 2016 & 2017 & 2018 & $\begin{array}{c}2019 \\
\text { (noviembre) }\end{array}$ \\
\hline $\begin{array}{c}\text { Personas extranjeras } \\
\text { presentadas ante la } \\
\text { autoridad migratoria }\end{array}$ & 127149 & 198141 & 188595 & 93846 & 138612 & 179335 \\
\hline
\end{tabular}

Fuente: Elaboración propia con datos proporcionados por la Unidad de Política Migratoria de la Secretaría de Gobernación. Disponible en: http://www.politicamigratoria.gob.mx/es/PoliticaMigratoria/ Boletines_Estadisticos

\section{Tabla 3}

\begin{tabular}{|c|c|c|c|c|}
\hline Año & 2015 & 2016 & 2017 & 2018 \\
\hline Número de expedientes & 2921 & 2339 & 2707 & 2915 \\
\hline
\end{tabular}

Fuente: Elaboración propia con datos obtenidos del Informe Anual de la Comisión Nacional de los Derechos Humanos. Disponible en: http://informe.cndh.org.mx/Default.aspx 


\section{Gráfica 2}

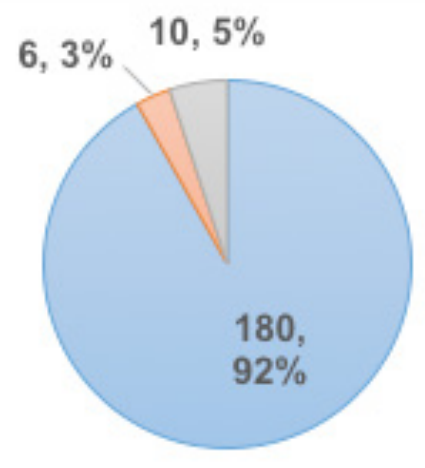

\section{$\square$ Nulidad lisa y llana $\quad \square$ Nulidad para efectos}

\section{$\square$ Validez del acto}

Fuente: Elaboración propia con información proporcionada por el Tribunal Federal de Justicia Administrativa mediante oficio UE-SI-0853/2018.

\section{Gráfica 6}

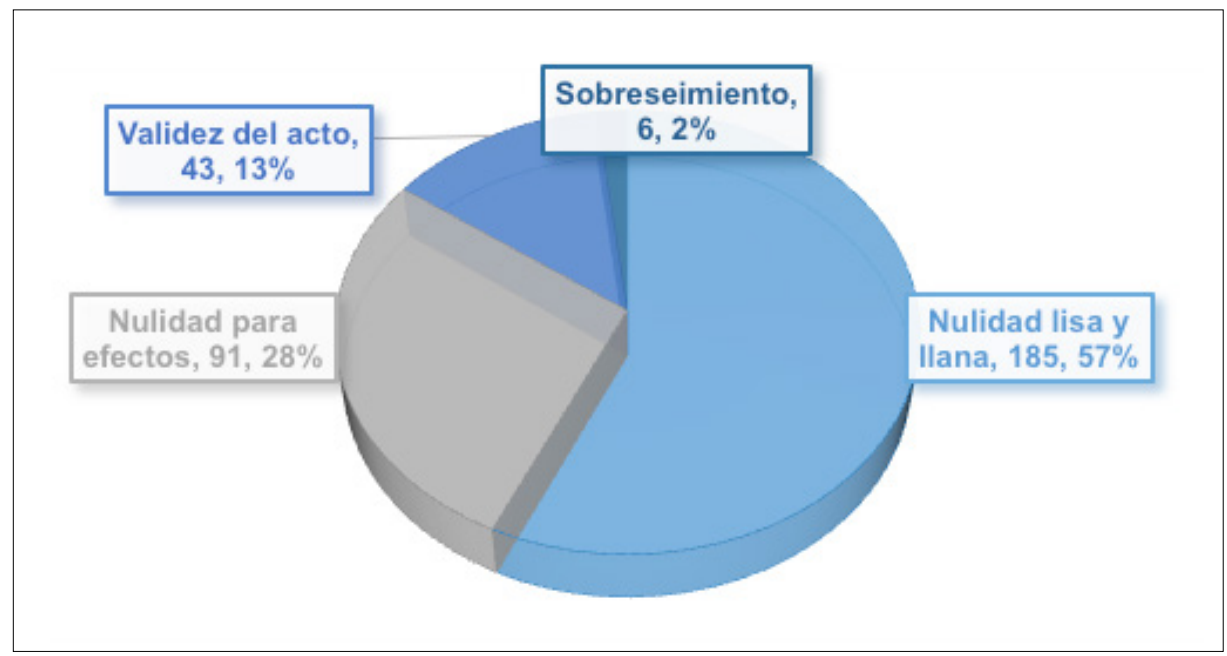

Fuente: Elaboración propia con información proporcionada por el Tribunal Federal de Justicia Administrativa mediante oficio UE-SI-0853/2018. 